\title{
Un vivo depletion of murine CD8 positive $T$ cells impairs survival during infection with a highly virulent strain of Cryptococcus neoformans
}

\author{
Christopher H. Mody, ${ }^{1}$ Gwo-Hsiao Chen, ${ }^{2}$ Catherine Jackson, ${ }^{2}$ Jeffrey L. Curtis ${ }^{2,3}$ \& Galen B. \\ Toews ${ }^{2,3}$ \\ ${ }^{1}$ Department of Internal Medicine, University of Calgary, Calgary, Alberta, Canada $;{ }^{2}$ Division of \\ Pulmonary \& Critical Care Medicine, Department of Internal Medicine, University of Michigan, Ann \\ Arbor, Michigan, USA; ${ }^{3}$ Department of Veterans Affairs Medical Center, Ann Arbor, Michigan, USA
}

Received 22 March 1993; accepted in revised form 26 July 1993

\begin{abstract}
Cell-mediated immunity plays an important but incompletely understood role in host defense against Cryptococcus neoformans. Because of their multiple capacities as cytokine-secreting cells, cytotoxic cells, and antigen-specific suppressor cells, CD8 positive T lymphocytes could potentially either enhance or impair host defense against $C$. neoformans. To determine whether CD8 $\mathrm{T}$ cells enhance or inhibit host defence during an infection with a highly virulent strain of $C$. neoformans, we examined the effect of in vivo CD8 cell depletion on suNival and on the number of organisms in mice infected by either the intratracheal or intravenous routes. Adequacy of depletion was confirmed both phenotypically and functionally. Regardless of the route of infection, we found that survival of mice depleted of CD8 T cells was significantly reduced compared to undepleted mice. Surprisingly, however, CD8 depletion did not alter organism burden measured by quantitative CFU assay in mice infected by either route. These data demonstrate that $\mathrm{CD} 8$ positive $\mathrm{T}$ cells participate in the immune response to a highly virulent strain of $C$. neoformans. By contrast to minimally virulent isolates that do not cause a life threatening infection, the immune response to a highly virulent isolate does not alter the burden of organisms, but does enhance host defense as it is necessary for the optimal survival of infected mice.
\end{abstract}

Key words: Cryptococcus, Host defense, Lymphocyte subsets, Mice, Mixed Lymphocyte Reaction

Abbreviations: ${ }^{3} \mathrm{H}$-TdR $-{ }^{3} \mathrm{H}$-thmidine; CFU - colony forming units; FITC - Fluorescein isothiocyanate; MLR - mixed lymphocyte reaction; PBS - phosphate buffered saline

\section{Introduction}

Cryptococcus neoformans is a worldwide pathogen that predominantly infects patients with defects in cell mediated immunity, especially those with the acquired immune deficiency syndrome (AIDS) [1-3]. C. neoformans is believed to be acquired by inhalation, in most cases without leading to symptomatic infection [4]. In some cases, however, $C$. neoformans induces a variety of pulmonary infections [5-7]. Additionally, the organism may induce lethal meningitis, frequently in patients without demonstrable lung infection [8]. These findings suggest that both pulmonary and systemic host defenses are essential to prevent cryptococcal infections. These defense mechanisms, complex and currently incompletely understood [9], must be better defined to permit development of immunomodulatory therapies or vaccines. 
Experimental models of cryptococcal infection clearly indicate the importance $T$ cell function for optimal host defense. CD4 positive $T$ cells protect mice infected with minimally virulent $[10,11]$ and highly virulent isolates of $C$. neoformans [12]. By contrast, $\mathrm{CD} 8$ positive $\mathrm{T}$ cells are heterogeneous in function and could either impair host defense to $C$. neoformans by acting as suppressor cells $[13,14]$ or enhance defenses by lysing infected macrophages or by secreting activating cytokines such as IFN- $\gamma[15,16]$. To determine the net effect of CD8 positive $T$ cells in host defenses it is necessary to examine their function using in vivo model systems. In this regard a particularly useful approach is ablation of specific cell types by monoclonal antibody treatment. Using this approach, it has recently been shown that CD8 positive $T$ cells are crucial for optimal host defense to infection of mice with minimally virulent strains of $C$. neoformans that do not result in a lethal infection $[10,11]$. However, the role of CD8 positive $T$ cells following inoculation with a highly virulent isolate of $C$. neoformans that does cause a lethal infection is unknown. Further, it has recently been shown that $\mathrm{CD} 8$ positive $T$ cells are crucial for optimal host defense to an intrapulmonary cryptococcal infection $[10,11]$. However, the role of $\mathrm{CD} 8$ positive $\mathrm{T}$ cells following intravenous inoculation, which mimics the stage of intravascular dissemination that leads to fatal meningitis, is unknown.

We performed the present experiments to determine the effect of CD8 T cell depletion during a life-threatening infection due to $C$. neoformans. Mice depleted of CD8 positive $T$ cells by monoclonal antibody injections in vivo were challenged by the intratracheal route (which mimics natural pulmonary infection) or by the intravenous route (which mimics disseminated infection). We found that depletion of CD8 positive T cells decreased survival of mice infected with highly virulent $C$. neoformans by either route, indicating the importance of this cell type in both phases of infection. Surprisingly, however, depletion of CD8 positive $T$ cells did not reduce the organism burden in the lungs or other organs.

\section{Methods}

Mice. Specific pathogen-free C57B1/6 $\left(\mathrm{H}-2^{\mathrm{b}}\right)$, $\mathrm{Balb} / \mathrm{c} \mathrm{nu} / \mathrm{nu}, \mathrm{CBA} / \mathrm{Ca},\left(\mathrm{H}-2^{\mathrm{k}}\right)$ and B6.C-H-2 bm1 (mutated $\mathrm{H}-2 \mathrm{~K}^{\mathrm{b}}$ ) mice were obtained from Jackson Laboratories (Bar Harbor, ME) or Banton Kingman (Fremont, CA). Mice were housed in a sterile laminar flow, specific pathogen-free environment. Mice were tested routinely for mycoplasma, Sendai virus, and mouse hepatitis virus. Mice were given mouse chow and water ad libitum.

Antibodies. The hybridoma YTS 169.4 was a generous gift of $\mathrm{H}$. Waldmann (University of Cambridge, Cambridge, UK) [17, 18]. YTS 169.4 produces a monoclonal antibody (rat IgG2b) that binds to murine CD8. Monoclonal antibodies were isolated and purified using previously described methods [12]. Briefly, hybridomas were grown as ascites in pristane-treated $\mathrm{BALB} / \mathrm{c}$ nu/nu mice [19]. The monoclonal antibody was purified from ascites by protein A column chromatography (MAPS II, Biorad, Richmond, CA). The monoclonal antibody was dialyzed into phosphate buffered saline (PBS) and quantified by spectrophotometry (Beckman, Palo Alto, CA) at 280 nanometers. Monoclonal antibody purity was tested by SDS-PAGE. For immunofluorescent staining, monoclonal antibody GK1.5 (anti-CD4) was generated and purified as previously described [12]. Anti-Thy 1.2 was obtained from Becton Dickinson (Mountain View, CA). Fluorescein isothiocyanate (FITC)-conjugated goat anti-rat $F\left(a^{\prime}\right) 2$ was obtained from Jackson Immunoresearch (West Grove, PA). Rat IgG was obtained from Cappell (Westchester, PA).

Preparation of $C$. neoformans and cryptococcal antigen. C. neoformans strain 145 serotype A (145A) was a generous gift of Judith Domer (Tulane University, New Orleans, LA). Strain 145A is highly virulent in mice and can induce $100 \%$ mortality [12]. C. neoformans organisms were maintained on Sabouraud's slants (Difco, Detroit, MI) and passaged to fresh slants monthly. 
To produce an inoculum, the organisms were passed to Sabouraud's broth containing 1\% neopeptone and $2 \%$ dextrose (Difco) and were grown for 48 hours at $35^{\circ} \mathrm{C}$. Significant clumping was not observed with this strain. Immediately before inoculation, organisms were counted by hemocytometer. The count was verified by making serial 10-fold dilution of the inocula, plating them on Sabouraud's agar and counting the number of colony forming units (CFU) at 48 hours. Hemocytometer counts were invariably $\log _{10}=0.1-0.3$ greater than the CFU determined by agar spread plates. Inoculum size was expressed as $\log _{10} \pm$ sem.

Depletion of $C D 8$ positive $T$ cells in vivo. Antibody was administered to mice by the intraperitoneal route. One hundred $\mu \mathrm{g}$ of YTS 169.4 or rat IgG (control) were placed into $200 \mu l$ of normal saline. Treatments were given two days before inoculation with $C$. neoformans (day -2 ), the day of inoculation (day 0 ), two days after inoculation $($ day +2$)$, and weekly thereafter (days +7 , $+14,+21$, etc.). Mice depleted of CD8 positive $T$ cells are frequently maintained in our facility for greater than 100 days without difficulty.

Infection of mice with $C$. neoformans. For intravenous inoculation, $0.5 \mathrm{ml}$ of normal saline containing $C$. neoformans was injected into the lateral tail vein of unanesthetized mice. Intratracheal inoculation was performed as previously described [22]. Briefly, mice were anesthetized with pentobarbital $\left(80 \mathrm{mg} \mathrm{kg}^{-1}\right)$, placed in the supine position, and the trachea was exposed. The trachea was intubated with a blunt steel needle advanced through the mouth. A plastic cannula (PE-10 tubing, Clay Adams, Parsippany, NJ) was passed through the steel needle until the tip of the plastic cannula was $2.6 \mathrm{~cm}$ from the teeth. Five microliters of normal saline containing $C$. neoformans was deposited in the trachea by injecting $100 \mu \mathrm{l}$ of air. To quantitate the size of the delivered inoculum, five mice were killed immediately after inoculation and the numbers of CFU deposited in the lungs was deter- mined. For this purpose, lungs were removed aseptically and were placed in sterile plastic bags containing $2 \mathrm{ml}$ sterile water. The bags were next mechanically disrupted in a tissue stomacher (Stomacher Lab Blender 80, Tekmar Co., Cincinnati, $\mathrm{OH})$. Next, the lung tissue was ground in a $15 \mathrm{ml}$ Ten Broeck tissue grinder (Fisher Scientific, Pittsburgh, PA). Serial 10 -fold dilutions were made and the numbers of CFU determined by plating on Sabouraud's agar.

Experimental protocols. After antibody injection, infected mice were divided into groups and the following experiments were performed. To confirm the adequacy of CD8 depletion, infected mice were killed and cells from peripheral blood, spleen, peripheral lymph nodes, and lungs were analyzed by immunofluorescence staining and flow cytometry. To further confirm functional depletion of CD8 positive $\mathrm{T}$ cells, in separate experiments the spleens of uninfected C57B1/6 mice were placed in mixed lymphocyte reactions (MLR) and proliferative responses measured. These experiments examined the response both to fully allogeneic stimulator cells and to stimulator cells that differ only at a single MHC class I locus. To determine the effect of CD8 depletion on host defense against $C$. neoformans, we performed both survival studies and analysis of organism clearance as described below.

Tissue harvesting for lymphocyte staining and $M L R$ generation. Seven days after inoculation, C57Bl/ 6 mice were deeply anesthetized and $1 \mathrm{ml}$ of blood withdrawn from the retro-orbital plexus was placed into tubes containing heparin (Microtainer, Becton Dickinson). The mice were killed by exsanguination and the spleen, peripheral (axillary and inguinal) lymph nodes, and lungs were removed. The erythrocytes in the peripheral blood sample were lysed by incubation with Tris$\mathrm{NH}_{4} \mathrm{Cl}$ for 5 minutes at $4{ }^{\circ} \mathrm{C}$; the remaining cells were washed three times with Hanks balanced salt solution with centrifugation at $400 \times g$ for 10 minutes between washes. Spleens were passed through a 60 -mesh stainless steel sieve. The eryth- 
rocytes were lysed and the remaining cells were incubated on a nylon wool column to purify $\mathrm{T}$ cells [23]. Nylon wool-nonadherent cells were eluted from the column and washed as above. Lymph nodes were processed in the same manner as the spleens but without erythrocyte lysis. Lungs were minced with scissors to $1-2 \mathrm{~mm}$ size and suspended in collagenase 150 units $\mathrm{ml}^{-1}$ (Sigma, Chemicals, St. Louis, MO) for one hour at $37^{\circ} \mathrm{C}$. Next, erythrocytes were lysed and the remaining cells purified on a nylon wool column.

Quantification of $T$ cell subsets. Immunofluorescence staining and flow cytometry were performed as previously described [12]. Briefly, one million cells of each tissue type were incubated with $50 \mu \mathrm{l}$ of either anti-Thy 1.2 (1/10 dilution), anti-CD8 (YTS $169.4 ; 5 \mu \mathrm{g}$ ), or anti-CD4 (GK1.5; $5 \mu \mathrm{g}$ ). The secondary staining antibody consisted of $30 \mu 1$ of a $1 / 20$ dilution of FITC-labeled $F\left(a b^{\prime}\right)_{2}$ fragment of goat anti-rat IgG (Jackson Immunoresearch). Control samples were incubated with the secondary antibody alone. Cells were analyzed for forward angle and $90^{\circ}$ light scatter and green fluorescence by flow cytometry, using an EPIC flowcytometer (Coulter, Hialeah, FL). Only cells expressing forward angle and $90^{\circ}$ light scatter characteristics of lymphocytes were analyzed.

Measurement of mixed lymphocyte reaction $(M L R)$. Nylon wool non-adherent splenocytes prepared as described above from CD8-depleted C57B1/6 mice were used as responder cells in an MLR. Responder cells were suspended in round bottomed wells of 96 well microtiter plates at $5 \times 10^{5} \mathrm{ml}^{-1}$ in complete medium, which consisted of RPMI 1640 containing $10 \%$ fetal bovine serum, $2 \mathrm{mM}$ glutamine, 100 units $\mathrm{ml}^{-1}$ penicillin, $100 \mu \mathrm{g} \mathrm{ml}^{-1}$ streptomycin, $0.2 \mu \mathrm{g} \mathrm{ml}^{-1}$ amphotericin $\mathrm{B}, 1 \mathrm{mM}$ sodium pyruvate (all from GIBCO, Grand Island, NY), $2.5 \times 10^{-5} \mathrm{M} 2$ mercaptoethanol (Sigma), and $0.1 \mathrm{mM}$ non-essential amino acids (Whittaker, Walkerville, $\mathrm{MD)}$. As stimulator cells, we used irradiated (2500 rads) splenocytes from either of two differ- ent mouse strains: CBA/Ca mice, which are fully allogeneic to C57B1/6 mice and thus differ at both MHC class I and class II loci; and B6.C-H-2 bm1 mice, which are identical to $\mathrm{C} 57 \mathrm{Bl} / 6$ mice except for a 3 amino acid substitution in the gene coding for the $\mathrm{H} 2-\mathrm{K}$ molecule [24] and thus differ only at a class I locus. Stimulator cells were add to quadruplicate miaotiter wells containing C57Bl/6 responder cells at concentrations of 0 (control), $2.5 \times 10^{5}$ or $5 \times 10^{5}$ cells per well in medium. Cultures were incubated in $5 \% \mathrm{CO}_{2}$ at $37^{\circ} \mathrm{C}$ until optimal proliferation was achieved (3 days for bm1 stimulator cells, or for 4 days for $\mathrm{CBA} / \mathrm{Ca}$ stimulator cells), and then were pulse with $1 \mathrm{uCi}$ per well $3 \mathrm{H}$-thymidine $(3 \mathrm{H}-\mathrm{TdR})$. Sixteen hours later, cells were harvested and incorporated radioactivity was determined as cpm using a liquid scintillation counter.

Survival and clearance studies. Separate groups of mice were used for survival and clearance studies. For survival studies, groups of 10 to 12 mice were infected with $C$. neoformans by either the intratracheal or intravenous routes, observed until moribund and then anesthetized and killed. For cryptococcal clearance studies, five mice from both experimental and control groups were killed at various times during infection induced by either the intratracheal or intravenous routes. Lungs, spleen, liver, kidney, and brain were removed and individually processed in the stomacher and tissue grinder as described above for the lung. Cryptococcal CFU in each organ were quantified on Sabouraud's agar plates. Sabouraud's agar did not contain antibiotics, and contaminating organisms were seldom detected.

Statistical analysis. Values are expressed as mean\pm SEM. The significance of difference between control and experimental groups was calculated by the unpaired two-tailed Student's t-test, or analysis of variance for multiple comparisons, and a significant difference accepted at $p<0.05$. 


\section{Results}

Phenotypic and functional evidence of CD8 depletion. Flow cytometric analysis confirmed that the monoclonal antibody treatment protocol used in these experiments markedly reduced numbers of CD8 positive $T$ cells from peripheral blood, lymphoid organs and lungs of mice infected with $C$. neoformans. In the blood, CD8 positive lymphocytes were reduced from $24 \%$ in control mice to $2 \%$ in mice that received YTS 169.4. CD8 lymphocytes were reduced in the lung from $17 \%$ to $4 \%$, in the spleen from $22 \%$ to $5 \%$, and in lymph nodes from $31 \%$ to $1 \%$. Thus, similar to previous reports [11], we confirm that the monoclonal antibody YTS 169.4 depletes CD8 lymphocytes in vivo. Functional evidence of CD8 lymphocyte depletion was obtained from experiments evaluating the MLR in CD8 depleted and normal animals. Depletion of CD8 T cells selectively abolished proliferative responses to MHC class I but not class II antigens (Fig. 1). Control C57Bl/6 mice treated with rat $\mathrm{IgG}$ mounted a vigorous response to stimulator cells from $\mathrm{B} 6 . \mathrm{C}-\mathrm{H}-2 \mathrm{bm} 1$ mice, from which they differ only at a mutation within the $\mathrm{H}-2 \mathrm{~Kb}$ locus, a class I difference (Fig. 1A). Treatment with YTS 169.4 almost totally abolished this response. By contrast, treatment with YTS 169.4 did not decrease the response of C57Bv6 splenocytes to fully allogeneic stimulator cells from $\mathrm{CBA} / \mathrm{Ca}$ mice, from which they also differ at MHC class II loci (figure 1B). These results indicate complete depletion of alloreactive CD8 positive $T$ cells with preservation of alloreactive $\mathrm{CD} 4$ positive $\mathrm{T}$ cells.

Effect of CD8 cell depletion on survival of mice infected with a highly virulent strain of $C$. neoformans. Depletion of CD8 positive $\mathrm{T}$ cells significantly decreased survival of mice infected with strain 145A, a highly virulent strain of $C$. neoformans. This adverse effect on survival was seen both in mice inoculated by the intratracheal route (Fig. 2) and in mice inoculated intravenously (Fig. 3). In the control mice inoculated by the intratracheal route, the first mouse died on day
39 , the mean survival was $51.3 \pm 2.4$ days, and the last mouse died on day 65. By contrast, in the CD8-depleted mice inoculated by the intratracheal route, the first mouse died on day 38 , the mean survival was $44.2 \pm 1.3$ days $(p<0.02)$, and the last mouse died only 51 days after inoculation. In the control mice inoculated by the intravenous route, the first mouse died on day 17 , the mean survival was $26.4 \pm 2.5$ days, and the last mouse died on day 43. By contrast, in the CD8-depleted mice inoculated by the intravenous route, the first mouse also died on day 17 , but the mean survival was $20.3 \pm 0.7$ days $(p<0.04)$, and the last mouse died only 24 days after inoculation. Taken together, these results indicate that $\mathrm{CD} 8$ positive $T$ cells contribute to optimal host defense during both the initial pulmonary phase and the subsequent hematogenous dissemination of cryptococcal infection.

Effect of CD8 depletion on clearance of $C$. neoformans. Clearance studies suggested that the adverse effect of $\mathrm{CD} 8$ depletion in vivo in $\mathrm{C} 57 \mathrm{Bl} / 6$ mice inoculated with strain $145 \mathrm{~A}$ was not due simply to a difference in reduction of organism burden (Table 1). After inoculation by the intratracheal route, CD8-depleted $\mathrm{C} 57 \mathrm{Bl} / 6$ mice had the same organism burdens initially, at sixteen days (data not shown), and at 28 days as control C57Bl/6 mice injected with rat IgG (Table 1). Similar results were seen in $\mathrm{C} 57 \mathrm{Bl} / 6$ mice inoculated by the intravenous route and assayed at 15 days (data not shown) and 21 days (Table 1).

\section{Discussion}

Our results demonstrate that: (1) CD8 positive T cells are depleted functionally (abrogation of a class I MHC restricted MLR) and phenotypically in mice receiving injections of anti-CD8 monoclonal antibody (YTS 169.4), (2) CD8 positive $\mathrm{T}$ cells are crucial to the survival of mice infected with a highly virulent strain of $C$. neoformans, both during initial pulmonary infection and during the phase of hematogenous dissemination and 


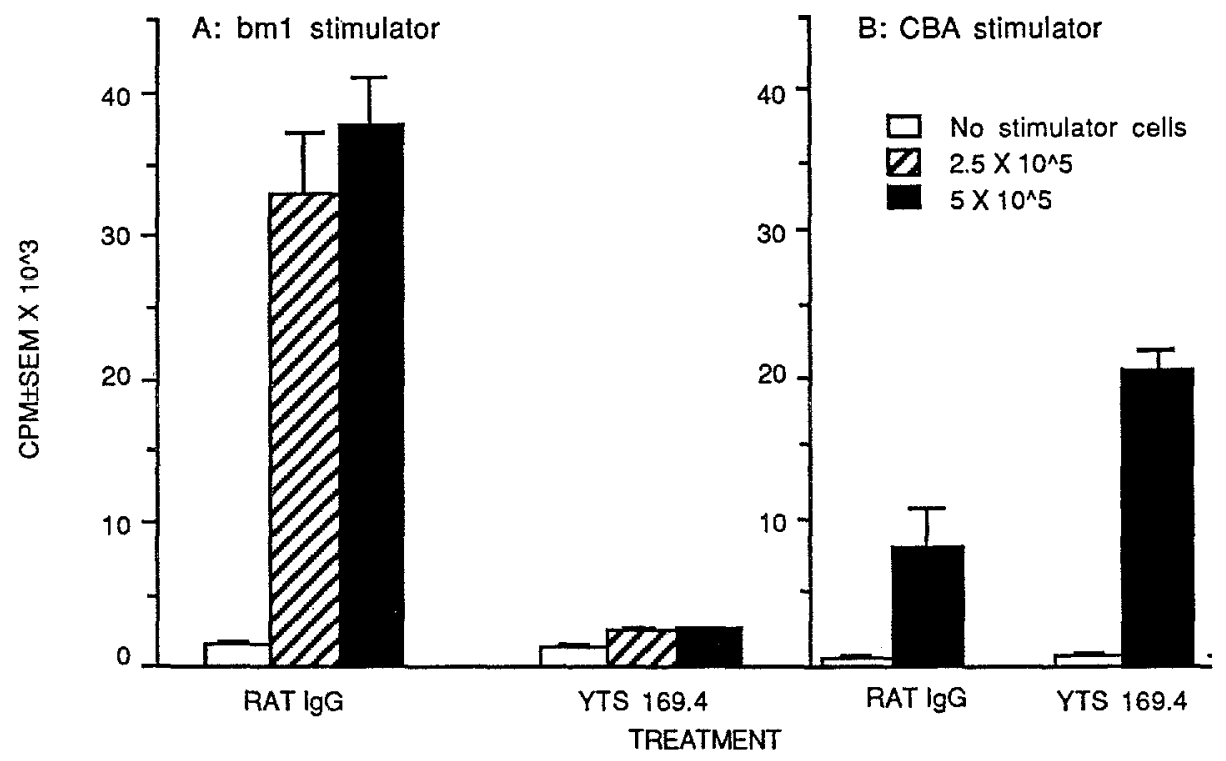

Fig. 1. Effect of CD8 depletion in vivo on the ability of splenocytes to respond in a mixed lymphocyte reactions (MLR). C57B1/6 mice were treated with $100 \mu \mathrm{g}$ monoclonal antibody YTS 169.4 or rat $\operatorname{IgG}$ on days $-2,0$, and +2 . Spleens were removed on day +7 and $5 \times 10^{5}$ nylon wool-nonadherent cells were placed in each well of 96-well microtiter plates in a final volume of $0.2 \mathrm{ml}$ complete medium. As stimulators, splenocytes were irradiated ( $2500 \mathrm{rads}$ ) and added at $2.5 \times 10^{5}$ (cross-hatched bars) or $5 \times 10^{5}$ (black bars) cells per well. Control wells received no stimulator cells (open bars). Cultures were incubated for three days, pulsed with $1 \mathrm{uCi}$ per well $3 \mathrm{H}-\mathrm{TdR}$ and harvested 16 hours later. A: Stimulator cells from B6.C-H-2 bm1 mice. B: Stimulator cells from fully allogeneic CBA/Ca mice. Wells receiving irradiated stimulator cells of either strain alone incorporated less than $500 \mathrm{cpm}$. Data are mean \pm SEM of quadruplicate samples.

(3) Surprisingly, however, the adverse effect on survival could not be explained by an increase in organism burden in any organ of CD8-depleted mice infected by either route.

Optimal host defense against $C$. neoformans undoubtedly involves interaction between phagocytes and immunoregulatory lymphocytes $[9,12,16,25,26]$. The crucial role of $\mathrm{T}$ cells in defense against $C$. neoformans has been well established by the markedly increased susceptibility to lethal infection of inbred mice with genetic deficiencies of $T$ cell function $[11,20,27-29]$. The relative contributions of individual $\mathrm{T}$ cell subtypes, are being assessed using the technique of in vivo subset depletion by monoclonal antibody treatment. This technique has shown that CD4 positive $\mathrm{T}$ cells are required for optimal protection in mice infected with minimally virulent (strains $184 \mathrm{~A}, 52 \mathrm{D})[10,11]$ and highly virulent (strain 145A) isolates of $C$, neoformans [12]. Interestingly, in the latter study we found that depletion of CD4 cells did not reduce organism clearance from the lung. Because this finding suggested that other lymphocyte subsets were involved in clearance, we next studied the role of CD8 positive $\mathrm{T}$ cells.

Based on their heterogeneous functional capabilities, $\mathrm{CD} 8$ positive $\mathrm{T}$ cells could conceivably either enhance or reduce host defense to $C$. neoformans. $\mathrm{CD} 8$ positive $\mathrm{T}$ cells could enhance host defense to $C$. neoformans indirectly by producing cytokines such as IFN- $\gamma[30-32]$, which is capable of activating macrophages for anticryptococcal activity [16] or directly by functioning as cytotoxic cells. In the latter case, $\mathrm{CD} 8$ positive $\mathrm{T}$ cells could themselves impair cryptococcal growth, a capacity observed in vitro [15]. Additionally, CD8 positive $T$ cells may lyse infected macrophages (which 


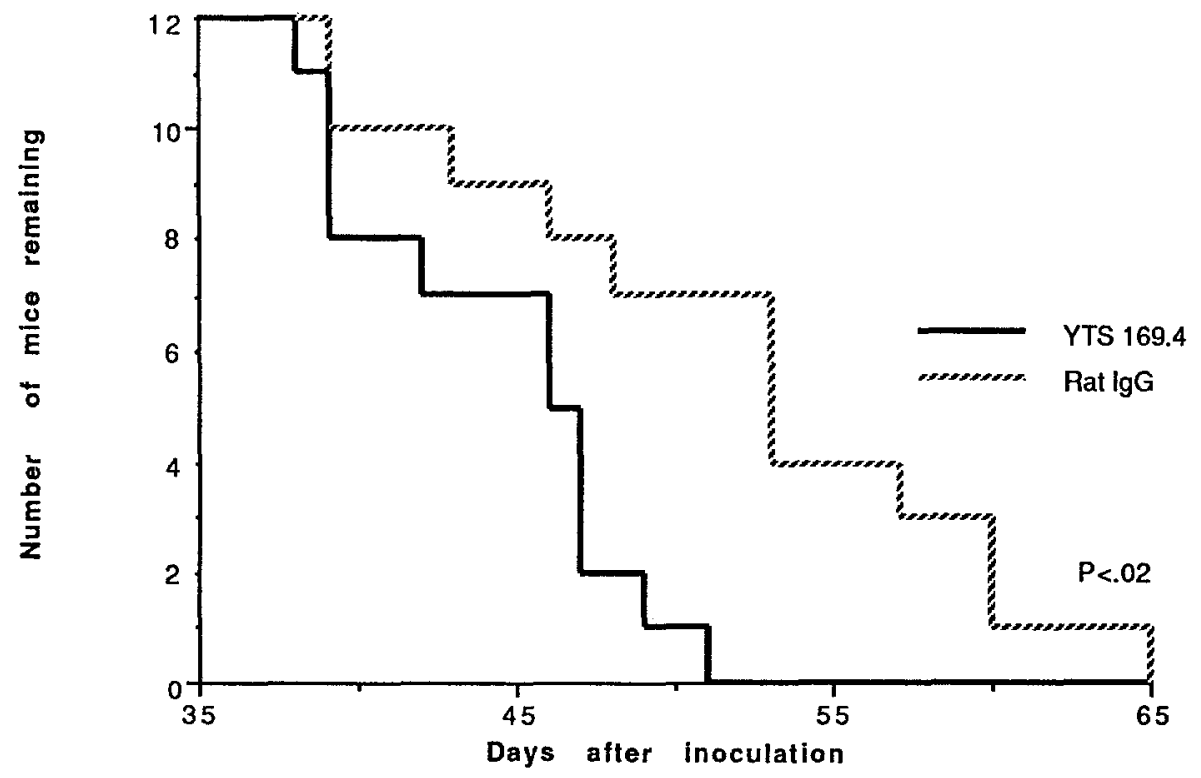

Fig. 2. Effect of CD8 lymphocyte depletion in vivo on survival of C57B1/6 mice infected intratracheally with a highly virulent strain of $C$. neoformans. C57B1/6 mice were treated with $100 \mu \mathrm{g}$ monoclonal antibody YTS 169.4 (heavy line) or rat IgG (light line) on days $-2,0,+2$, and +7 , and weekly thereafter. Mice were infected by the intratracheal route on day 0 with strain $145 \mathrm{~A}$ $C$. neoformans and the day of death recorded. The inoculum of $C$. neoformans deposited in the lungs was $\log _{10}=3.83 \pm 0.02 \mathrm{cfu}$.

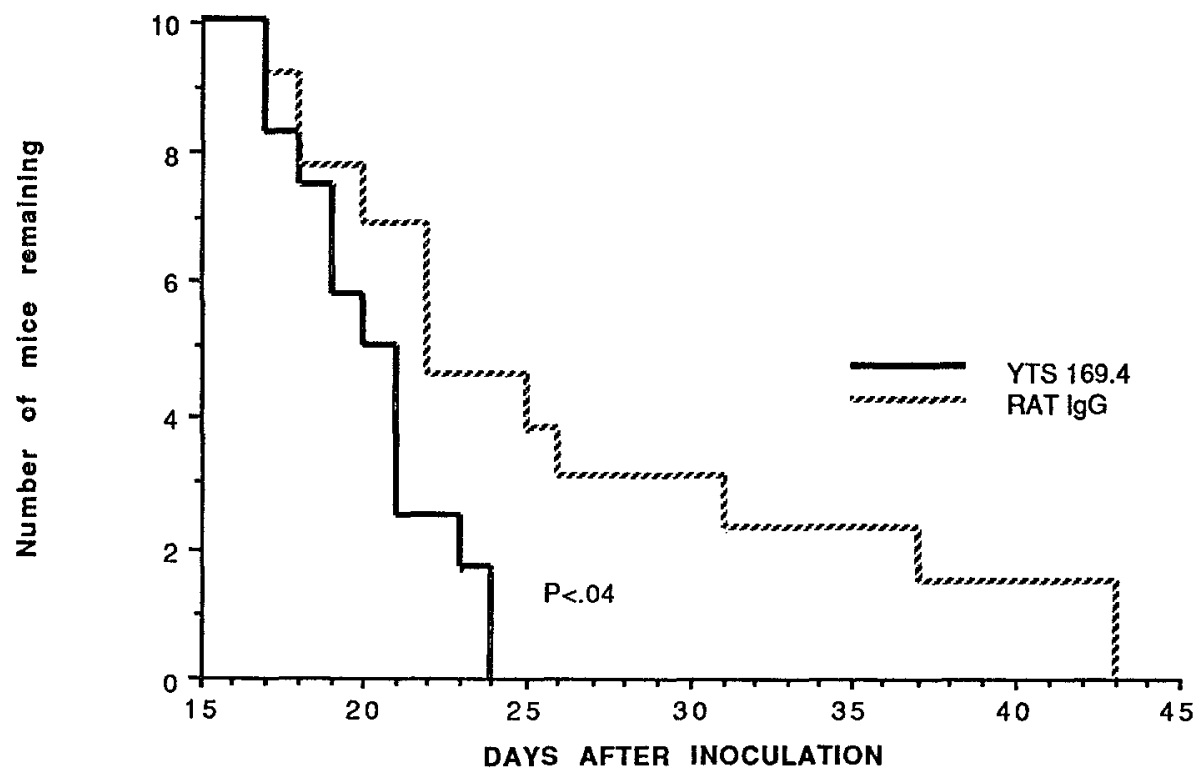

Fig. 3. Effect of $\mathrm{CD} 8$ lymphocyte depletion on survival of $\mathrm{C} 57 \mathrm{Bl} / 6$ mice infected intravenously with a highly virulent strain of C. neoformans. C57B1/6 mice were treated with $100 \mu \mathrm{g}$ monoclonal antibody YTS 169.4 (heavy line) or rat IgG (light line) on days $-2,0,+2$, and +7 , and weekly thereafter. Mice were infected by the intravenous route on day 0 with strain $145 \mathrm{~A} C$. neoformans and the day of death recorded. The inoculum of $C$. neoformans injected was $\log _{10}=3.74$. 
Table 1. Effect of CD8 cell depletion on burden of a highly virulent strain of $C$. neoformans in various organs

\begin{tabular}{|c|c|c|c|c|}
\hline \multirow[b]{3}{*}{ Organ } & \multicolumn{4}{|c|}{ Route of inoculation } \\
\hline & \multicolumn{2}{|l|}{ Intratracheal } & \multicolumn{2}{|l|}{ Intravenous } \\
\hline & Rat IgG & YTS 169.4 & Rat IgG & YTS 169.4 \\
\hline Lung & $6.57 \pm 0.08$ & $6.78 \pm 0.25 \mathrm{NS}$ & $3.30 \pm 0.40$ & $4.00 \pm 0.50 \mathrm{NS}$ \\
\hline Spleen & $2.80 \pm 0.04$ & $2.64 \pm 0.33 \mathrm{NS}$ & $3.92 \pm 0.24$ & $3.60 \pm 0.36 \mathrm{NS}$ \\
\hline Liver & $3.80 \pm 0.20$ & $3.62 \pm 0.24 \mathrm{Ns}$ & $4.33 \pm 0.44$ & $4.70 \pm 0.36 \mathrm{NS}$ \\
\hline Kidney & $2.44 \pm 0.13$ & $2.59 \pm 0.30 \mathrm{NS}$ & $3.76 \pm 0.14$ & $3.92 \pm 0.23 \mathrm{NS}$ \\
\hline Brain & $4.26 \pm 0.60$ & $4.38 \pm 0.44 \mathrm{NS}$ & $6.20 \pm 0.21$ & $6.45 \pm 0.42 \mathrm{NS}$ \\
\hline
\end{tabular}

Mice were treated with $100 \mu \mathrm{g}$ monoclonal antibody YTS 169.4 or rat $\operatorname{IgG}$ on days $-2,0,+2$, and +7 and weekly thereafter. Mice were infected with strain $145 \mathrm{~A} \mathrm{C}$. neoformans on day 0 by the indicated route. At various times later, mice were killed and cryptococcal burden determined by plating serial dilutions of macerated organs on Sabouraud's agar plates. All data are Log 10 cfu as mean \pm SEM of five mice per group. In the mice inoculated intratracheally, the initial inoculum was $\log _{10}=4.50 \pm 0.30$ cfu and mice were assayed at day 28 . In the mice inoculated intravenously, the initial inoculum was $\log _{10}=2.38 \mathrm{cfu}$ and mice were assayed at day 21 . NS $=$ not significant $(p>0.05$, unpaired Student's $t$ test $)$.

inefficiently kill ingested organisms of some $C$. neoformans strains $[33,34])$. Such a lytic action, which has been demonstrated in vitro for murine macrophages infected with Leishmania mexicana [35], would be anticipated to limit translocation of viable organisms to other organs [36]. Alternately, CD8 positive $\mathrm{T}$ cells function as suppressor cells following immunization with soluble cryptococcal antigen $[9,13]$. Our data indicate that the net effect of CD8 positive T cells during infection with strain $145 \mathrm{~A}$ is to enhance host defense.

We believe that it is essential that strain variation in cryptococcal virulence be considered in investigations of host defenses against cryptococci. Cryptococci of different strains have been known for some time to differ in virulence in experimental model systems. It is possible, but currently unproven, that strain-specific differences in virulence explain why serious cryptococcal infection at times occurs in patients who are not obviously immunocompromised. The molecular basis for strain-specific differences in virulence is uncertain. Various strains of $C$. neoformans exhibit stable differences in capsular size in vitro and this difference has been found by some investigators to correlate with differences in virulence $[37,38]$. Cryptococcal polysaccharide, the major capsular constituent, blocks phago- cytosis of $C$. neoformans by macrophages $[39,40]$, inhibits lymphocyte proliferation in vitro $[41,42]$ and induces profound immunosuppression when injected into mice [43]. However, other more detailed studies have indicated that capsular size alone does not completely predict virulence $[44,45]$. It is likely that additional virulence factors exist. One such factor could be the ability of the host immune system to recognize the pathogen and respond by the generation of a specific immune response.

In the present experiments, it was important to determine that in vivo monoclonal antibody treatment produced a defect in recognition and proliferation by CD8 positive $\mathrm{T}$ cells. For this purpose, we evaluated the capacity of CD8-depleted splenic lymphocytes to respond to class I disparate cells from B6.C-H-2 bm1 mice. Class I $\mathrm{MHC}$ molecules of $\mathrm{B} 6 . \mathrm{C}-\mathrm{H}-2 \mathrm{bm} 1$ mice are identical to those of $\mathrm{C} 57 \mathrm{Bl} / 6$ mice except for a 3 amino acid substitution in the $\mathrm{H} 2-\mathrm{K}$ molecule [24]. Exposure of $\mathrm{CD} 8$ positive $\mathrm{T}$ cells from C57Bl/6 mice to bm1 splenocytes have previously been shown to lead to a vigorous MLR [46]. Therefore, the observed abrogation of the response of $\mathrm{B} 6$ to $\mathrm{bm} 1$ by in vivo administration of YTS 169.4 confirmed functional depletion of CD8 positive $\mathrm{T}$ cells. The selectivity of this in vivo depletion was confirmed by the observation that 
splenocytes from mice treated with YTS 169.4 proliferated normally to fully allogeneic splenocytes from $\mathrm{CBA} / \mathrm{Ca}$ mice.

The mechanism whereby depletion of CD8 positive $T$ cells impairs survival of mice infected with strain 145A C. neoformans is unknown. We investigated the possibility that depletion of CD8 positive $\mathrm{T}$ cells decreases organism clearance. Previous studies that used minimally virulent strains of $C$. neoformans (strain 52D, strain 184A) found that depletion of CD8 positive $\mathrm{T}$ cells resulted in an increased burden of cryptococci in lungs, brain, and spleen after intratracheal inoculation $[10,11]$. While CD8 positive cells play an important role in organism's clearance following infection with minimally virulent organisms, that mechanism is clearly not applicable in cryptococcal infection of C57Bv6 mice with strain 145A C. neoformans by either the intratracheal or the intravenous route. Thus, it is apparent that CD8 positive $T$ cells (and potentially their functional subsets) are capable of contributing to crucial anticryptococcal defense by different mechanisms depending on organism virulence. At present the mechanisms are elusive since it is not technically feasible to selectively deplete mice of only cytotoxic or only cytokine-releasing CD8 positive $\mathrm{T}$ cells. An alternative approach to this end would be to selectively replete $\mathrm{T}$ cell deficient nude or scid mice with selected $\mathrm{T}$ cell clones.

We found that the number of organisms were not altered by CD 8 lymphocyte depletion. A possibility to explain the current results is that a protective DTH response might 'wall of' the organism as previously suggested [47]. This might localize $C$. neoformans to small areas with high concentrations of organisms and improve survival without altering the overall number of organisms recoverable from an organ. We have found that CD8 cells are important in DTH to $C$. neoformans [48]. If this response was partially mediated by CD8 positive lymphocytes, then it might explain increased survival without decreasing the burden of organisms. Altemately, CD8 positive $\mathrm{T}$ cells might limit the release or effects of a toxic substance produced by $C$. neoformans that would improve survival without altering the burden of organisms. Since the mortality of mice is related to the cellular infiltration, and resulting cerebral edema [49], it is possible that depletion of CD8 positive $T$ cells suppress the immune response that leads to cerebral edema without altering the burden of organisms. A final possibility is that CD8 positive $T$ cells are crucial for determining the balance between $T_{h} 1$ and $T_{h} 2 C D 4$ positive $T$ cell subsets [50]. The balance between these two subsets, which differ in cytokine production, is crucial to the outcome of several parasitic infections $[51,52]$. Whether a similar dependence on $\mathrm{CD} 4$ positive $\mathrm{T}$ cell subsets pertains in cryptococcosis is currently unknown. As mentioned previously, $\mathrm{CD} 8$ positive $\mathrm{T}$ cells can secrete IFN- $\gamma$, which has been shown in culture to inhibit induction of $\mathrm{T}_{\mathrm{h}} 2 \mathrm{CD} 4$ positive $\mathrm{T}$ cells [53]. We are actively exploring expression of $T_{h} 1$ and $T_{h} 2 C D 4$ positive $T$ cell subsets in experimental infection of mice with several strains of cryptococci.

In summary, we have shown that $\mathrm{CD} 8$ positive $T$ cells are necessary for optimal murine host defense to a highly virulent strain of $C$. neoformans. These results complement previous observations that CD8 positive $\mathrm{T}$ cells are also essential for optimal defense against less virulent strains of $C$. neoformans $[10,11]$ (in the latter case at least in part by reducing the organism burden). It is possible that the beneficial effects of CD8 positive $\mathrm{T}$ cells could be enhanced even in partially CD4deficient hosts if cryptococcal antigens recognized by CD8 positive $\mathrm{T}$ cells were used. Thus, strategies designed to stimulate this population of cells should be explored as immunotherapy against this ubiquitous fungal pathogen.

\section{Acknowledgments}

This research was supported in part by research grants from the Medical Research Council of Canada (CHM); the Alberta Lung Association (CHM); the Department of Veterans Affairs 
(JLC, GBT); the Office of the Vice President for Research, University of Michigan (JLC); NIH grants HL 29543 and HL 39672 (GBT); and Specialized Center of Research in Occupational and Immunologic Lung Diseases (JLC, GBT) from the USPHS. Dr. Mody is a Clinical Investigator of the Alberta Heritage Foundation for Medical Research.

We thank Dr Mary Lipscomb and for many helpful discussions. We thank Claire Rogers for technical assistance with flow cytometry, and Alana Williamson and Catherine Meyers for secretarial assistance.

\section{References}

1. Chuck SL, Sande MA. Infections with Cryptococcus neoformans in the acquired immunodeficiency syndrome. $\mathrm{N}$ Engl J Med 1989; 321: 794-99.

2. Levitz S. The ecology of Cryptococcus neoformans and the epidemiology of cryptococcosis. Rev Inf Dis 1991; 13: 1163-69.

3. Zuger A, Louie E, Holzman RS, Simberkoff MS, Rahal JJ. Cryptococcal disease in patients with the Acquired Immune Deficiency Syndrome. Ann Int Med 1986; 104: 234-40.

4. Bodet CAI, Graybill JR. Cryptococcal pulmonary disease. Orlando: Grune \& Stratton, 1986.

5. Baker R, Haugen R. Tissue changes and tissue diagnoses in cryptococcosis. Am J Clin Pathol 1955; 25: 14-24.

6. Gal A, Koss M, Hawkins J, Evans S, Einstein H. The pathology of pulmonary cryptococcal infections in the acquired immunodeficiency syndrome. Arch Pathol Labl Med 1986; 110: 502-7.

7. Kerkering TM, Duma RJ, Shadomy S. The evolution of pulmonary cryptococcosis: Clinical implications from a study of 41 patients with and without compromising host factors. Ann Int Med 1981; 94: 611-16.

8. Meyer RD, Holmberg K. Fungal Infections in HIV-infected patients. In: Holmberg K, Meyer RD, eds. Diagnosis and therapy of systemic fungal infections. New York: Raven Press, 1989: 79-100.

9. Murphy JW. Immunoregulation in cryptococcosis. Immunol Res $1989 ; 47: 319-45$.

10. Hill JO, Harmsen AG. Intrapulmonary growth and dissemination of an avirulent strain of Cryptococcus neoformans in mice depleted of CD4 + or CD8 + T cells. J Exp Med 1991; 173: 755-58.

11. Huffnagle GB, Yates JL, Lipscomb MF. Immunity to a pulmonary Cryptococcus neoformans infection requires both CD4+ and CD8 + T cells. J Exp Med 1991; 173: $793-800$.

12. Mody CH, Lipscomb MF, Toews GB. Depletion of
$\mathrm{CD} 4+(\mathrm{L} 3 \mathrm{~T} 4+)$ lymphocytes in vivo impairs murine host defense to Cryptococcus neoformans. J Immunol 1990; 144: $1472-77$.

13. Murphy JW, Mosley RL, Moorghead JW. Regulation of cell-mediated immunity in cryptococcosis , II: Characterization of first-order $\mathrm{T}$ supressor cells and induction of second-order suppressor cells. J Immunol 1983; 130: 2876-81.

14. Murphy JW, Mosley RL. Regulation of cell mediated immunity in cryptococcosis, III: Characterization of second-order $\mathrm{T}$ suppressor cells (Ts2). J Immunol 1985; 134: $577-84$

15. Fung PYS, Murphy JW. In vitro interactions of immune lymphocytes and $C$. neoformans. Infect Immun 1982; 36: 1128-38.

16. Mody CH, Tyler CL, Sitrin RG, Jackson C, Toews GB. Interferon-gamma activates rat alveolar macrophages for anticryptococcal activity. Am J Resp Cell Mol Biol 1991; 5: $19-26$.

17. Cobbold SP, Jayasuriya A, Nash A, Prospero TD, Waldmann $H$. Therapy with monoclonal antibodies by elimination of T-cell subsets in vivo. Nature 1984; 312: 548-51.

18. Galfre $G$, Milstein C, Wright B. Rat $\times$ rat hybrid myelomas and a monoclonal anti-Fd portion of mouse IgG. Nature 1979; 277: 131-3.

19. Hoogenraad N, Helman T, Hoogenraad J. The effect of pre-injection of mice with pristane on ascites tumor formation and monoclonal antibody. J Immunol Methods 1983, 61: 317-20.

20. Cauley LK, Murphy JW. Response of congenially athymic [nude] and phenotypically normal mice to Cryptococcus neoformans infections. Infect Immun 1979;23: 644-51.

21. Dubois M, Gilles JK, Hamilton PA, Rebers PA, Smith F. Colorimetric method for the determination of sugars and related substances. Anal Chem 1956; 28: 350-56.

22. Mody CH, Toews GB, Lipscomb MF. Cyclosporin-A inhibits the growth of Cryptococcus neoformans in a murine model. Infect Immun 1988; 56: 7-12.

23. Julius $\mathrm{MH}$, Simpson E, Herzenberg LA. A rapid method for the isolation of functional thymic-derived murine lymphocytes. Eur J Immunol 1973; 3: 645-49.

24. Hansen TH, Spinella DG, Lee DR, Shreffler DC. The immunogenetics of the mouse major histocompatibility gene complex. Ann Rev Genet 1984; 118: 99-129.

25. Lipscomb MF, Alvarellos T, Toews GB, Tompkins R, Evans Z, Koo G. Role of natural killer cells in resistance to C. neoformans in mice. Am J Path 1987, 128: 354-61.

26. Mody CH, Toews GB, Lipscomb MF. Treatment of murine cryptococcosis with cyclosporin-A in normal and athymic mice. Am Rev Respir Dis 1989; 139: 8-13.

27. Graybill JR, Craven PC, Mitchell LF, Drutz DJ. Interaction of chemotherapy and immune defenses in experimental murine cryptococcosis. Antimicrob Agents Chemother 1978; 14: 659-67.

28. Marquis G, Montplaisir S, Pelletier M, Mousseau S, Auger P. Genetic resistance to murine cryptococcosis increase susceptibility in the CBA/N XID muted strain. Infect Immun 1985; 47: 282-87.

29. Salkowski CA, Balish E. A monoclonal antibody to 
gamma interferon blocks augmentation of natural killer cell activity induced during systemic Cryptococcosis. Infect. Immun 1991; 59: 486-93.

30. Gessner A, Moskophidis D, Lehmann-Grube F. Enumeration of single IFN-gamma-producing cells in mice during viral and bacterial infection. J Immunol 1989; 142: $1293-$ 98.

31. Johnson HM, Torres BA. Phorbol ester replacement of helper cell and interleukin- 2 requirements in gamma interferon production. Infect. Immun 1982; 36: 911-14.

32. Schofield L, Villaquiran J, Ferreira A, Schellekens H, Nussenzweig R, Nussenzweig V. Gamma interferon, $\mathrm{CD} 8+\mathbf{T}$ cells and antibodies required for immunity to malaria sporozoites. Nature 1987; 330: 664-66.

33. Bolanos B, Mitchell TG. Phagocytosis and killing of Cryptococcus neoformans by rat alveolar macrophages in the absence of serum. J Leuk Biol 1989; 46: 521-28.

34. Bolanos B, Mitchell TG. Killing of Cryptococcus neoformans by rat alveolar macrophages. J Med Vet Mycology 1989, 27: 219-28.

35. Smith LE, Rodrigues M, Russell DG. The interaction between CD8 + cytotoxic T cells and Leishmania-infected macrophages. J Exp Med 1991; 174: 499-505.

36. Harmsen AG, Muggenberg B, Snipes M, Bice D. The role of macrophages in particle translocation from lungs to lymph nodes. Science $1985 ; 230: 1277-80$.

37. Bulmer G, Sans M, Gunn C. Cryptococcus neoformans, Nonencapsulated mutants. J Bacteriol 1967; 94: 1475-79.

38. Drouhet E, Segretain G, Aubert J. Polyside capsulaire d'un champignon pathogene Torulopsis neoformans: Relation avec la virulence. Ann Inst Pasteur Paris 1950; 79: $891-900$.

39. Kozel TR, Gotschlich EC. The capsule of Cryptococcus neoformans passively inhibits phagocytosis of the yeast by macrophages. J Immunol 1982; 129: 1675-80.

40. Mitchell TG, Friedman L. In vitro phagocytosis and intracellular fate of variously encapsulated strains of Cryptococcus neoformans. Infect Immun 1972; 5: 491-98.

41. Collins HL, Bancroft GJ. Encapsulation of Cryptococcus neoformans impairs antigen-specific T-cell responses. Infect Immun 1991; 59: 3883-88.

42. Mody $\mathrm{CH}$, Syme RM. Effect of polysaccharide capsule and methods of preparation on human lymphocyte prolif- eration in response to Cryyptococcus neoformans. Infect. Immun 1993; 61: 464-69.

43. Kozel TR, Gulley WF, Cazin J. Immune response to Cryptococcus neoformans soluble polysaccharide: Immunological unresponsiveness. Infect Immun 1977; 18: 7017.

44. Dykstra MA, Friedman L, Murphy JW. Capsule size of Cryptococcus neoformans: control and relationship to virulence. Infect Immun 1977; 16: 129-35.

45. Littman M, Tsubura E. Effect of degree of encapsulation upon virulence of Cryptococcus neoformans. Proc Soc Exp Biol Med 1959; 101: 773-77.

46. Sprent J, Schaefer M, Korngold R. Functions of purified L3T4+ and Lyt-2 + cells in vitro and in vivo. Immunol Rev 1986; 91: 195-218.

47. Hill JO. CD4+ T cells cause multinucleated giant cells to form around Cryptococcus neoformans and confine the yeast within the primary site of infection in the respiratory tract. J Exp Med 1992; 175: 1685-95.

48. Mody CH, Paine R, Jackson CJ, Toews GB. CD8 cells mediate delayed hypersensitivity following intrapulmonary infection with Cryptococcus neoformans. Chest 1993; 103: 118s.

49. Dromer F. Charreire J. Improved amphotericin-B activity by a monoclonal anti-Cryptococcus neoformans antibody: Study during murine cryptococcosis and mechanism of action. J Infect Dis 1991; 163: 1114-20.

50. Mosmann TR, Coffman RL. TH1 and TH 2 cells: different pattems of lymphokine secretion lead to different functional properties. Annu Rev Immunol 1989; 7: 145-73.

51. Finkelman F, Pearce E, Urban JJ, Sher A. Regulation and biological function of helminth-induced cytokine responses. Immunol Today 1991; 12: 62-66.

52. Locksley RM, Scott P. Helper T-cell subsets in mouse leishmaniasis: Induction, expansion and effector function. Immunol. Today 1991; 12: A58-A61.

53. Gajewski TF, Fitch FW. Anti-proliferative effect of IFNgamma in immune regulation, I: IFN-gamma inhibits the proliferation of Th2 but not Th1 murine helper lymphocyte clones. J Immunol 1988; 140: 4245-52.

Address for correspondence: Christopher H. Mody, MD, Division of Pulmonary Medicine, Room 273 HMRB; 3330 Hospital Drive NW, University of Calgary, Calgary, Alberta, Canada, T2N 4N1

Phone: (403) 220-8479; Fax: (403) 283-4740 